\title{
The Management Accounting Practices in Healthcare: The Case of Czech Public Hospitals
}

\author{
Josef Krupička*
}

\begin{abstract}
:
The economic and demographical development in Europe in the last few decades has led to increased pressure on effectiveness in the healthcare industry. The growing importance of performance management in this industry resulted in agreater focus on management accounting practices capable of providing managers with relevant information to support their decision-making activity. This article presents the results of the survey examining the management accounting practice among the economic managers in public hospitals in the Czech Republic. The results from total of 60 respondents pointed out to management accounting practices being well established and rather conventional with the budgeting being the most relevant. Further results offer explanation of enabling factors of potential efficiency gains beneficial for managerial practice.
\end{abstract}

Key words: Management accounting practices; Healthcare performance management; Czech Republic.

JEL classification: M41; I11.

\section{Introduction}

Over the last few decades, European countries have experienced gradual increase of healthcare expenditures in terms of their share on GDP nearing almost onetenth of the total economic activity in EU28 since 2013 (OECD/EU, 2018). Given that healthcare systems across Europe are predominantly funded by public sources, this development has led to increased pressure on cost control in the form of implementation of various cost-containment policies (Schwietz, 2016). However, as Erixon \& Van der Marel (2011) argue, cost-containment policies can only achieve marginal effects, and the government should instead address the inefficiencies in the delivery of healthcare services. The evidence from various countries suggests that up to one-fifth of health care spending is wasteful and could be reallocated to a better use (OECD/EU, 2018). Yet to address

Josef Krupička; University of Economics, Prague, Faculty of Finance and Accounting, Department of Management Accounting, W. Churchill Sq. 4, 130 67, Prague 3, Czech Republic, <josef.krupicka@vse.cz>, ORCID ID: 0000-0003-4092-2491.

This article is supported by the project Effect of remuneration system and performance measurement system on employee motivation and behavior registered by Internal Grant Agency of the University of Economics, Prague, No. F1/25/2018. 
Krupička, J.: The Management Accounting Practices in Healthcare: The Case of Czech Public Hospitals.

the aspects of efficiency on the institutional level, the appropriate performance measurement and control mechanisms need to be established to adequately support the decisions on resource allocation and effectiveness. Closer inspection of the diverse management accounting (MA) practices in various healthcare settings might in turn help the managers to understand these practices better and to find the most appropriate mix of practices for their settings. Nevertheless, a close attention should be paid to the contextual factors when doing so. While there has already been done much research work in the area related to the MA practices in healthcare from both the overall and national perspectives (Malmmose, 2019; Eldenburg et al., 2017), there still exist many research possibilities in countries which to date have been examined only scarcely. Therefore, this research aims to contribute to this research area by presenting the evidence on the MA practices in national settings of the Czech healthcare and thus expand the knowledge base for further learning.

\section{Performance Management in the Healthcare Environment}

The concept of performance measurement in the healthcare system is a highly complex issue due to the challenging nature of this environment (Cylus et al., 2016; Hussey et al., 2009). As Cylus et al. (2016) note about the healthcare system, there exists a seemingly infinite set of interlinked processes that could be evaluated independently, and while the indicators of such processes might give a glimpse of certain aspects of inefficiency, they rarely offer a comprehensive overview. Yet the role of performance measurement is crucial as it provides the informational basis for the management to influence the organisational performance via standardised MA practices combining both the aspects of measurement and management. Studies often mention the New Public Management approach leading to a greater focus on performance management in healthcare across the European countries (Simonet, 2011), though with an unclear impact on the actual performance (Alonso et al., 2015).

In their cross-country comparison of the healthcare spending efficiency, Joumard et al. (2010) conclude that none of the compared healthcare systems performed systematically better in the delivery of cost-effective healthcare. They also note that adopting the best policy practices from similar healthcare system settings in combination with the most appropriate elements from other systems might yield an increase in the healthcare spending efficiency (Joumard et al., 2010). However, any comparison of the healthcare system performance should always be accompanied by explanation of the key differences in national settings to avoid possible misinterpretation of the acquired information (Papanicolas \& Smith, 2013). In their effort to improve the cost-effectiveness of healthcare systems, European countries have adopted various cost-containing policies of which 
the most impactful appear to be application of hard global budgets in combination with activity-based payments (Schwietz, 2016; O’Reilly et al., 2012).

Performance management on the institutional level is besides the national healthcare system' settings influenced also by the specific aspects of performance measurement systems. The regulation on costing practices defines the cost object that becomes a focus of the analysis (e.g., DRG) and affects the indirect cost allocation mechanism (Eldenburg et al., 2017; Chapman et al., 2016). Further factors to consider are the ownership form (Eldenburg et al., 2017; Anderson, 2012) and the presence of unions (Koys et al., 2012). The extent of influence of these aspects may vary and thus creates a diverse contextual environment requiring application of the most appropriate mix of management control practices, since for example the ownership form affects the management's focus on the organisational profit and thus should stimulate the use of profitabilityfocused practices.

However, the most performance-influential MA practices appear to be those that improve cost-consciousness (Pizzini, 2006). As Pizzini (2006) concludes in an empirical study examining the relation between the cost-system design, the managers' evaluation of the relevance and usefulness of the cost data and performance, functional cost systems supply the managers with more relevant data which they in turn use to make performance-enhancing decisions. Studies examining the implementation of activity-based costing (ABC) in healthcare (Popesko et al., 2015; Jericó \& Castilho, 2010) often promote informational supremacy of this costing practice over more conventional costing practices, such as absorption costing, especially in the area of inpatient care where the costs arise primarily in relation to activities and procedures. But the challenges associated with the implementation of $\mathrm{ABC}$ necessitated its modification resulting in the development of the time-driven ABC (Keel et al., 2017; Campanale et al., 2014; Kaplan \& Anderson, 2003).

While the appropriate choice of costing practice is important, it serves as an information basis in a much broader concept of performance measurement. The Balanced Scorecard (BSC) serves as such concept, allowing managing and measuring the performance of specific actions in their relation to the company strategy (Inamdar et al., 2002). The studies examining implementation of BSC in the healthcare industry provide some evidence of its beneficial effect on the hospital performance (Gao \& Gurd, 2014; Lin et al., 2014). While the MA practices differ one from the other, they seem to have a positive influence on performance when providing the hospital management with the relevant information. Hence the relevance of these practices for the decision-making activity of the hospital management might indicate their informational value just as their suitability for the examined environment. 
Krupička, J.: The Management Accounting Practices in Healthcare: The Case of Czech Public Hospitals.

\section{Contextual Background of MA Practices in Czech Healthcare}

In the Czech Republic, healthcare expenditures in 2017 represented 7.1\% of GDP, which is well below the EU28 average of $9.6 \%$ (OECD/EU, 2018). More than $80 \%$ of these expenditures are funded from public sources, while out-of-pocket payments cover the rest. Being based on the principle of solidarity, the funding system of statutory health insurance is based on the compulsory membership in any of the public health insurance funds which are subordinated to the Ministry of Health and act as purchasers of the service from the healthcare providers. While the healthcare service covered by statutory health insurance is universal in general, the actual scope of the covered service is defined by a combination of the regulating mechanisms such as the legislation, listing of the range of covered procedures, or the arrangements between health insurance funds and healthcare providers defining the terms of reimbursement as well as the volume of the service.

While in total there are almost forty thousand healthcare providers ranging from the local practitioners to large teaching hospitals, there is a group of healthcare providers accounting for half of the 2017 national healthcare expenditures (IHIS CR, 2018) and thus essentially determining the performance of the system as a whole. This group includes 72 public hospitals directly governed either by the ministries or by the regional government bodies, and the service they provide comprises of outpatient and inpatient care. While the outpatient care reimbursement is based on the capped fee-for-service scheme, the inpatient care reimbursement is determined by the combination of global budgets, diagnosisrelated group (DRG) system and the individual contracts between hospitals and health insurance funds.

Considering its impact on hospital management, the reimbursement settings determine the object to which the hospital management seeks to relate the costs and revenues to be able to manage the efficiency in healthcare delivery. Whereas this is a manageable task for outpatient care, where both costs and revenues arise from a specific medical service, it is a considerably more challenging issue in the case of inpatient care, representing almost $60 \%$ of hospital expenditures (OECD/EU, 2018). In essence, the reimbursement for inpatient care is determined by inclusion of the patient in the DRG and the revenue can be directly attributed to the patient. The costs arise from the direct medical treatment (e.g., surgery) and any complementary medical service (e.g., laboratory tests) where the cost driver is the activity itself. Additionally while the measure of activities related to the given patient may vary and thus accounts for the differences among patients, the reimbursement does not change, since the idea of the DRG system assumes that patients with similar diagnoses require a similar level of treatment. Studies dealing with this issue (Popesko et al., 2015; Jericó \& Castilho, 2010) advise 
the use of $\mathrm{ABC}$ practice as being able to more accurately determine the cost of the patient case in comparison to absorption costing. However, to date there have not been created any official regulations or guidelines promoting the use of this practice in larger scale.

On the contrary, the budgeting practice should be well spread among the public hospitals, since these are subjected to the rules of budgetary responsibility (Act No. 23/2017, Coll.) due to their ownership form. In accordance with this legislation, public hospitals are obliged to annually compile a new budgeting outlook for up to three following years and the hospital management is this expected to consider the consequences of its decisions beyond the current period. However, the legislation regulating the compilation of financial statements (Decree No. 312/2014, Coll.) defines the recognition for revenues arising from the healthcare provision covered by the health insurance funds on the cash basis, despite the general use of accrual-based accounting in the Czech public sector. This approach makes the linkage between the service rendered and the revenue recognised less transparent and the information value of budgeting practice for management is thus limited.

As Alexa et al. (2015) in their analysis of the Czech healthcare system point out, the reliance on public expenditures makes the healthcare system vulnerable during economic turndowns when the allocations may be reduced. While there is an acute need for a financial reform, the issue remains unaddressed due to the lack of political consensus. Considering all its characteristics, the whole system has a potential for an increase in efficiency which remains to be possibly exploited both on the system level as well as on the institutional level to which the use of the proper MA practices might contribute.

\section{Research Methodology}

In line with the research aim, the research tasks were established as the task to identify both the MA practices relevant for public hospital managers in the Czech Republic (M) and the contextual factors influencing their relevance (F) and the task to examine the relationship between the identified MA practices and the contextual factors. The survey approach was used in the form of an online questionnaire whose design was consulted beforehand with the representatives of the target population in order to ensure its clarity and comprehensiveness. This approach resulted in identification of 21 variables for examination as presented in Table 1. The target population of the survey was identified as 72 public hospitals directly governed by the public sector due to their overall share on the healthcare expenditures and due to the similar size of institutions in this group mitigating the possible influence of company size (e.g., Guilding 
Krupička, J.: The Management Accounting Practices in Healthcare: The Case of Czech Public Hospitals.

et al., 2000). The respondents were the managers responsible for the economic performance and the governance of the management control systems in the public hospitals assuming them to be the most competent for the survey due to their understanding of the examined MA practices. In the survey, the respondents were asked to evaluate the relevance of each variable for their performance-related decision-making activity on the 7-point equidistant scale with the minimum score representing the complete irrelevance and the maximum score representing the absolute relevance.

\section{Tab. 1 Examined variables}

\begin{tabular}{ll|ll}
\hline Var. & Description & Var. & Description \\
\hline M1 & Absorption costing & F1 & Contracts with health insurance funds \\
M2 & Variable costing & F2 & Average cost of service \\
M3 & Target costing & F3 & Pricing policy \\
M4 & Patient costing & F4 & Accounting information \\
M5 & AB costing/TDABC & F5 & Management information system \\
M6 & Budgeting & F6 & Patient feedback \\
M7 & Benchmarking internal & F7 & Ownership \\
M8 & Benchmarking competitive & F8 & Technological innovation \\
M9 & Balanced Scorecard & F9 & Labour unions \\
M10 & Responsibility centres & F10 & Strategic \& process maps \\
M11 & Analysis of financial statements & & \\
\hline
\end{tabular}

Source: authorial compilation.

All the hospitals were reached by a phone call about the research intention with the outcome determining the sample size of 60 possible respondents due to the duplicity in the management of different hospitals arising from their shared governance or the respondent's position being vacant without adequate deputy at that time. Gathered data were analysed using the descriptive statistics to determine the relevance of examined variables and the correlation analysis to examine the relationship between the variables. A two-tailed t-test was used in correlation analysis to test the significance of correlation coefficients with the base hypothesis of independence tested on a confidence level of $99 \%$. 


\section{Results and Discussion}

The survey was conducted in the summer of 2018 and resulted in 43 fully completed questionnaires representing a $71.7 \%$ response rate in the sample. This response rate was above the average response rate usually achieved in management accounting studies (Van der Stede et al., 2005) and met the requirements for the minimum sample size calculated using the Cochran's sample size formula for continuous data and the Cochran's correction formula (Cochran, 1977).

Tab. 2 Descriptive statistics for examined variables

\begin{tabular}{llll|llll}
\hline Var. & Mean & St. dev. & Min/Max & Var. & Mean & St. dev. & Min/Max \\
\hline M1 & 5.326 & 1.782 & $1 / 7$ & F1 & 6.744 & 0.441 & $6 / 7$ \\
M2 & 5.093 & 1.770 & $1 / 7$ & F2 & 6.140 & 1.246 & $3 / 7$ \\
M3 & 5.140 & 1.807 & $1 / 7$ & F3 & 4.791 & 1.226 & $2 / 7$ \\
M4 & 5.047 & 1.914 & $1 / 7$ & F4 & 6.372 & 0.846 & $4 / 7$ \\
M5 & 3.163 & 2.058 & $1 / 7$ & F5 & 6.093 & 0.971 & $4 / 7$ \\
M6 & 6.581 & 0.957 & $3 / 7$ & F6 & 5.698 & 1.423 & $2 / 7$ \\
M7 & 5.605 & 1.466 & $1 / 7$ & F7 & 5.628 & 1.619 & $1 / 7$ \\
M8 & 5.628 & 1.346 & $1 / 7$ & F8 & 5.023 & 1.012 & $4 / 7$ \\
M9 & 3.930 & 1.969 & $1 / 7$ & F9 & 4.372 & 1.273 & $2 / 7$ \\
M10 & 6.326 & 1.358 & $1 / 7$ & F10 & 3.721 & 1.453 & $1 / 7$ \\
M11 & 3.651 & 1.824 & $1 / 7$ & & & & \\
\hline
\end{tabular}

Source: Results of survey (2018) + authorial computation.

The descriptive statistics for costing practices (M1-M5) suggest their importance for the decision-making activity of public hospital management except for $\mathrm{ABC}$ (M5) which presents an opportunity for further development as the literature recommend shifting from the traditional costing practices towards more sophisticated approaches, such as ABC (Rauliajtys-Grzybek et al., 2017; Popesko et al., 2015). Scores achieved by budgeting (M6) confirm its dominant role in this environment, as observed also by other studies (King et al., 2010; Smith et al., 2006), and corresponded with the research expectations. Compared to the costing practices, benchmarking practices (M7-M8) appear to be more favoured in healthcare as these practices serve not only to compare the performance but also to observe and learn the best practices. While the relevance of BSC (M9) appears to be rather modest, the results for the responsibility centres (M10) 
Krupička, J.: The Management Accounting Practices in Healthcare: The Case of Czech Public Hospitals.

support the notion of a decentralised management. The moderate results for the analysis of financial statements (M11) raise the possible question of to what extent the managers consider the impacts of their decision-making activity on financial statements.

The hospital managers agreed on the critical role of the arrangements with health insurance funds $(\mathrm{F} 1)$ as these determine the reimbursement framework for the provided inpatient care. Since the reimbursement for different DRG groups is mediated by the average cost of service (F2), its key role is not surprising. In contrast, the moderate results for hospital pricing policy (F3) reflect the lesser portion of services for which the public hospital can set a price. The results for the accounting information (F4) and the management information system (F5) suggest that the economic dimension of available information is more relevant for the hospital managers than the qualitative dimension represented by the patient feedback (F6). In comparison to other factors, the remaining contingency factors (F7-F9) appear to be less influential on the use of MA practices though still relevant unlike the factor of the existence of strategic and process maps (F10) of which were respondents rather ambivalent.

Tab. 3 Correlation coefficients passing the significance test

\begin{tabular}{lll|lll|lll}
\hline Var. & $\begin{array}{c}\text { Correl. } \\
\text { coeff. }\end{array}$ & \multicolumn{1}{c|}{ p-val } & Var. & $\begin{array}{c}\text { Correl. } \\
\text { coeff. }\end{array}$ & p-val & Var. & $\begin{array}{c}\text { Correl. } \\
\text { coeff. }\end{array}$ & p-val \\
\hline M1xM2 & 0.850 & 0.0000 & F1xF10 & 0.406 & 0.0069 & M1xF8 & 0.418 & 0.0053 \\
M2xM3 & 0.517 & 0.0004 & F2xF6 & 0.723 & 0.0000 & M1xF9 & -0.495 & 0.0007 \\
M3xM4 & 0.604 & 0.0000 & F2xF7 & 0.499 & 0.0007 & M2xF5 & 0.535 & 0.0002 \\
M4xM9 & 0.563 & 0.0001 & F3xF6 & 0.577 & 0.0001 & M3xF3 & 0.411 & 0.0062 \\
M7xM10 & 0.700 & 0.0000 & F3xF7 & 0.452 & 0.0024 & M4xF10 & 0.433 & 0.0037 \\
M8xM11 & 0.557 & 0.0001 & F5xF8 & 0.628 & 0.0000 & M5xF8 & 0.616 & 0.0000 \\
F1xF4 & 0.580 & 0.0000 & F5xF9 & -0.472 & 0.0014 & M6xF2 & 0.569 & 0.0001 \\
F1xF6 & 0.442 & 0.0030 & F6xF7 & 0.425 & 0.0045 & M6xF6 & 0.429 & 0.0041 \\
F1xF7 & 0.530 & 0.0003 & M1xF5 & 0.656 & 0.0000 & M9xF10 & 0.692 & 0.0000 \\
\hline
\end{tabular}

Source: Results of survey (2018) + authorial computation.

Out of the 210 tested pairs of variables during the correlation analysis, only the 27 variations presented above (Table 3) passed the test of significance with the desired confidence level. Closer inspection of these relationships in the context of identified relevance for the examined variables provided additional information about their inner dynamics. The results for the contextual factors correlating with the costing practices suggest the technology (F5, F8) being 
the key factor driving the use of costing practices in general. However, the less conventional the costing practices are, the more they correlate with the use of strategic approach in the management (F10) and the application of BSC (M9). While arrangements with the health insurance companies (F1) play a significant role in the managers' decision-making activity, this factor does not appear to have a significant influence on the use of any MA practice even when considering its inter-correlation with other factors. The interpretation is different in the case of the pricing policy (F3) and target costing (M3), where the possibility of setting the prices for the services covered by out-of-pocket payments represents the enabling factor for the use of this practice.

The relationships between the benchmarking practices (M7, M8), responsibility centres (M10) and analysis of the financial statements (M11) point out the complementary nature of these MA practices, although their use does not seem to be significantly correlated with the relevance of any contextual factor. Although being the most essential practice, the use of budgeting (M6) appears to be relatively independent of other practices and factors; except for the average cost of service (F2) and the patient feedback (F6), which possibly represent the management's effort of cost containment while considering its impact on the quality of provided services. Furthermore, this effort may be interpreted as the consequence of the form of governance since both contextual factors (F2, F6) appear to be interrelated with the relevance of ownership (F7). Whereas all the mentioned relationships represented positively correlated variables, the opposite results were obtained in the case of the negotiations with labour unions (F9), since these negotiations occupy the decision-making capacity of the hospital management that could otherwise be used to solve performance-related issues using the MA practices.

While these findings provide evidence of the importance of MA practices for the examined segment of public hospitals, it must be noted that the relevance of examined variables may be different in the case of private hospitals due to the different accent on organisational goals and strategies leading to the use of a possibly different mix of the MA practices. However, the hospital management in both ownership forms considers the ethical dimension of the decision-making activity as each assumed decision might not only influence the economic situation of the hospital but the quality of the care as well. This factor puts constrains on the decision-making activity of the hospital management and thus supports the notion of the MA practices used in private and public hospitals being similar irrespective of the factor of ownership. Nonetheless, only when private subjects are included into the future research there might come out a definitive answer on the similarity of practices in public 
Krupička, J.: The Management Accounting Practices in Healthcare: The Case of Czech Public Hospitals.

and private hospitals. This goal will be therefore incorporated into the further research aimed to enhance the information value of the presented findings.

\section{Conclusion}

Based on the results of the survey, it may be stated that management accounting practices are well established in the Czech healthcare, though the significance of different practices varies amongst the subjects in correspondence with the existing diversity of the examined environment. While the budgeting practice was identified as the most relevant practice for publicly governed hospitals in line with the literature, the current state of legislation possibly limits its effectiveness. Alignment of the revenue recognition approach in healthcare with the generally adopted accrual principle might be the right stimulus for the application of more sophisticated approaches and thus also for the mitigation of this limitation. The technological advance appears to be the key driver of using the costing practices, although the strong presence of traditional costing practices represents an opportunity for potential efficiency gains since the literature generally advise the use of $\mathrm{ABC}$ in the environment with a high share of inpatient care, a typical characteristic of public hospitals in the Czech Republic.

The diversity amongst the respondents regarding the application of more sophisticated management accounting practices, such as ABC or BSC, points out the existence of a narrower group of subjects considering the strategic dimension of their decision-making activity while using these practices. Closer analysis of this subgroup and the key drivers of their performance present the potential for knowledge gains if addressed by further research. While the arrangements with health insurance funds and the accounting information appear to be impactful on the decision-making activity of public hospital managers, these factors do not appear to be significant with regard to the relevance of the management accounting practices.

Drawing these conclusions, it must be noted that correlation does not equal causation, and most of the research results instead indicate the areas suitable for further examination with a narrower research focus. Also, while the precautions were made to mitigate the limitations of the survey approach, they cannot be entirely dismissed. Nonetheless, the identification of the relevant management accounting practices, contextual factors, and their mutual dynamics verified the potential for an increase in efficiency in the examined environment and pointed out the existing misalignment of current practice with the environmental characteristics. 


\section{References}

Alexa, J., Rečka, L., Votápková, J., van Ginneken, E., Spranger, A., Wittenbecher, F., 2015. Czech Republic: Health system review. In: Health Systems in Transition, 17(1), 1-165.

Alonso, J. M., Clifton, J., \& Díaz-Fuentes, D., 2015. The impact of New Public Management on efficiency: An analysis of Madrid's hospitals. Health Policy, 119(3), 333-340.

Anderson, S., 2012. Public, private, neither, both? Publicness theory and the analysis of healthcare organisations. Social Science \& Medicine, 74(3), 313-322.

Campanale, C., Cinquini, L., Tenucci, A., 2014. Time-driven activity-based costing to improve transparency and decision making in healthcare: a case study. Qualitative Research in Accounting \& Management, 11(2), 165-186.

Cochran, W. G., 1977. Sampling Techniques. New York: John Wiley and Sons.

Cylus, J., Papanicolas, I., Smith, P., 2016. Health system efficiency: how to make measurement matter for policy and management. Copenhagen, Denmark: World Health Organization.

Eldenburg, L. G., Krishnan, H. A., Krishnan, R., 2017. Management Accounting and Control in the Hospital Industry: A Review. Journal of Governmental \& Nonprofit Accounting, 6(1), 52-91.

Erixon, F., Van der Marel, E., 2011. What is driving the rise in health care expenditures? An inquiry into the nature and causes of the cost disease (No. 05/2011). European Centre for International Political Economy, Brussels, Belgium.

Gao, T., Gurd, B., 2014. Meeting the challenge in performance management: the diffusion and implementation of the balanced scorecard in Chinese hospitals. Health policy and planning, 30(2), 234-241.

Guilding, C., Cravens, K. S., Tayles, M., 2000. An international comparison of strategic management accounting practices. Management Accounting Research, 11(1), 113-135.

Hussey, P. S., de Vries, H., Romley, J., Wang, M. C., Chen, S. S., Shekelle, P. G., McGlynn, E. A., 2009. A Systematic Review of Health Care Efficiency Measures. Health Services Research, 44(3), 784-805.

Chapman, C. S., Kern, A., Laguecir, A., Quentin, W., 2016. Management accounting and efficiency in health services: the foundational role of cost analysis. In J. Cylus, I. Papanicolas, \& P. C. Smith (Eds.), Health system efficiency: how to make measurement matter for policy and management, 75-98. World Health Organization. 
Krupička, J.: The Management Accounting Practices in Healthcare: The Case of Czech Public Hospitals.

IHIS CR, 2018. Economic results of hospitals 2017. Available from: <uzis.cz/system/files/eknem2017.pdf>. [14 January 2019].

Inamdar, N., Kaplan, R. S., Reynolds, K., 2002. Applying the balanced scorecard in healthcare provider organizations. Journal of healthcare management, 47(3), 179-195.

Jericó, M. D. C., Castilho, V., 2010. Cost management: the implementation of the Activity-Based Costing method in sterile processing department. Revista da Escola de Enfermagem da USP, 44(3), 745-752.

Joumard, I., André, C., Nicq, C., 2010. Health Care Systems: Efficiency and Institutions. SSRN Electronic Journal.

Kaplan, R. S., Anderson, S. R., 2003. Time-driven activity-based costing. SSRN Electronic Journal.

Keel, G., Savage, C., Rafiq, M., Mazzocato, P., 2017. Time-driven activity-based costing in health care: A systematic review of the literature. Health Policy, 121(7), 755-763.

Kelley, K., Clark, B., Brown, V., Sitzia, J., 2003. Good practice in the conduct and reporting of survey research. International Journal for Quality in Health Care, 15(3), 261-266.

King, R., Clarkson, P. M., Wallace, S., 2010. Budgeting practices and performance in small healthcare businesses. Management Accounting Research, 21(1), 40-55.

Koys, D. J., Katz, M., Lavan, H., 2012. Unions and Hospitals: Quality, Patient Satisfaction, and Net Income. In Proceedings of 64th Annual Meeting, 78-88, Labor and employment Relations Association (LERA), Chicago (USA).

Lin, Z., Yu, Z., Zhang, L., 2014. Performance outcomes of balanced scorecard application in hospital administration in China. China Economic Review, 30, 115 .

Malmmose, M., 2019. Accounting research on health care - Trends and gaps. Financial Accountability \& Management, 35(1), 90-114.

O'Reilly, J., Busse, R., Häkkinen, U., Or, Z., Street, A., \& Wiley, M., 2012. Paying for hospital care: the experience with implementing activity-based funding in five European countries. Health Economics, Policy and Law, 7(1), 73-101.

OECD/EU, 2018. Health at a Glance: Europe 2018: State of Health in the EU Cycle. Paris: OECD Publishing.

Papanicolas, I., Smith, P., 2013. Health system performance comparison: an agenda for policy, information and research: an agenda for policy, information and research. McGraw-Hill Education (UK). 
Parker, L. D., 2012. Qualitative management accounting research: Assessing deliverables and relevance. Critical Perspectives on Accounting, 23(1), 54-70.

Pizzini, M. J., 2006. The relation between cost-system design, managers' evaluations of the relevance and usefulness of cost data, and financial performance: an empirical study of US hospitals. Accounting, Organizations and Society, 31(2), 179-210.

Popesko, B., Novák, P., Papadaki, Š., 2015. Measuring diagnosis and patient profitability in healthcare: economics vs ethics. Economics \& Sociology, 8(1), 234-245.

Rauliajtys-Grzybek, M., Baran, W., Macuda, M., 2017. Cost Accounting in Public Hospitals in Poland. Journal of Health Management, 19(2), 275-291.

Schwietz, C., 2016. Cost-Containment Policies in Hospital Expenditure in the European Union (No. 037/2016). Directorate General Economic and Financial Affairs (DG ECFIN), European Commission.

Simonet, D., 2011. The New Public Management Theory and the Reform of European Health Care Systems: An International Comparative Perspective. International Journal of Public Administration, 34(12), 815-826.

Smith, D. G., Wynne, J., 2006. Capital budgeting practices in hospitals. International Journal of Healthcare Technology and Management, 7(1/2), 117.

Van der Stede, W. A., Young, S. M., Chen, C. X., 2005. Assessing the quality of evidence in empirical management accounting research: The case of survey studies. Accounting, Organizations and Society, 30(7-8), 655-684. 
Krupička, J.: The Management Accounting Practices in Healthcare: The Case of Czech Public Hospitals. 